\title{
Iamque opus exegi: la oda III 30 de Horacio en palabras de Ovidio*
}

\author{
Ma Carmen Hoces Sánchez \\ Universidad de Granada \\ mhoces@ugr.es
}

Iamque opus exegi: the Ode III 30 of Horace in words of Ovid Estudio de las huellas de Horacio Carm. III 30
en Ovidio Met. XV 871-879, especialmente en el
léxico y la sintaxis.

Palabras clave: Horacio, Ovidio, huellas.
Study of Horace Carm. III 30 traces in Ovid Met. XV 871-879, specially in vocabulary and syntax.

Key words: Horace, Ovid, traces.

\section{Los textos}

Horacio cerraba la primera edición de sus carmina, en el año 23 a. C., con un poema en el que proclamaba su orgullo por la labor llevada a cabo y vaticinaba para sí, gracias a ella, una gloria imperecedera, que el paso del tiempo ha confirmado. Así se expresaba Horacio (Carm. III 30):

Exegi monumentum aere perennius regalique situ pyramidum altius, quod non imber edax, non Aquilo inpotens possit diruere aut innumerabilis annorum series et fuga temporum. non omnis moriar multaque pars mei uitabit Libitinam: usque ego postera

* Este trabajo se ha realizado dentro del proyecto "Ars grammatica y ars musica», FFI2012-36647, financiado por la Dirección General de Investigación del M.E.C. 
crescam laude recens, dum Capitolium scandet cum tacita uirgine pontifex. dicar, qua uiolens obstrepit Aufidus et qua pauper aquae Daunus agrestium regnauit populorum, ex humili potens princeps Aeolium carmen ad Italos deduxisse modos. sume superbiam quaesitam meritis et mihi Delphica lauro cinge uolens, Melpomene, comam.

Ovidio colocó al final de su gran obra, las Metamorfosis, los siguientes versos, compuestos bien obedeciendo a un plan inicial, bien al conocer su autor el decreto de su exilio o durante él ${ }^{1}$, a partir del año 8 d. C., (Met. XV 871-879):

Iamque opus exegi, quod nec Iouis ira nec ignis nec poterit ferrum nec edax abolere uetustas. cum uolet, illa dies, quae nil nisi corporis huius ius habet, incerti spatium mihi finiat aeui; parte tamen meliore mei super alta perennis astra ferar, nomenque erit indelebile nostrum; quaque patet domitis Romana potentia terris ore legar populi, perque omnia saecula fama, siquid habent ueri uatum praesagia, uiuam².

Es inevitable para cualquier lector de estos versos finales el pensar en la famosa oda de Horacio. Ovidio concluyó su gran obra con estos nueve versos a modo de sphragís, como antes que él habían hecho otros autores (griegos y latinos) y él mismo hizo en otras obras anteriores y posteriores a esta ${ }^{3}$, pero en este caso las palabras ovidianas evocan claramente las de Horacio, las recrean y reutilizan como un ejemplo más de esa habilidad ovidiana de refe-

${ }^{1}$ Las opiniones se dividen entre quienes creen que la obra no fue reelaborada en el destierro (Álvarez-Iglesias 2004 : 106-107), que el epílogo no es un añadido posterior (Wickkiser 1999) y los que creen que lo elaboró tras conocer el decreto de su destierro (por ejemplo, Pohlenz 1913, p.12).

${ }^{2}$ Los textos están tomados de las ediciones de Oxford, Wickham-Garrod 1901 (reimpr. 1975) la de Horacio, Tarrant 2004 la de Ovidio.

${ }^{3}$ Cf. Paratore 1958. 
rre idem aliter ${ }^{4}$, en palabras de Ovidio (Ars II 128) al referirse a Ulises que, ante las continuas preguntas de Calipso acerca de la caída de Troya, solía relatar lo mismo de otro modo. En este sentido, Ovidio, que cita nominalmente en su obra a numerosos poetas ${ }^{5}$, es además maestro en aludir sutilmente a ellos mediante otros procedimientos, como ocurre con Tibulo ${ }^{6}$, Lucrecio ${ }^{7}$, Virgilio $^{8}$ o el propio Horacio ${ }^{9}$.

Etiquetemos este pasaje ovidiano de evocación, reminiscencia, recreación o emulación, lo cierto es que los últimos versos de las Metamorfosis de Ovidio suenan mucho a Horacio. No es fácil dar con la intención que movió a Ovidio a cerrar los quince libros de su obra maestra con unos versos que recuerdan tanto al poeta lírico y son múltiples las cuestiones que entrarían en juego a la hora de responder a estas preguntas, como el significado de la presencia de un motivo lírico en una obra épica y la adecuación al género en que aparece, el momento en que Ovidio compuso este final (¿antes o después de conocer el decreto de exilio?), etc., así como las relaciones entre ambos autores, o mejor dicho, la actitud de Ovidio ante Horacio, si fue esta de admiración o de antipatía ${ }^{10}$, que opiniones hay en ambos sentidos. En cualquier caso, creo que aquí Horacio es el modelo libremente elegido ${ }^{11}$, que la referencia a él es de una gran carga estilística, que Ovidio, poeta lector e innovador, entabla una especie de juego con el lector ${ }^{12}$ en el que este reconoce el texto de origen y disfruta descubriendo y contemplando su mutata forma. Todo ello hace de este un pasaje de alto contenido narratológico, o poetológico, una prueba significativa de la autoconsciencia de la poesía ${ }^{13}$.

${ }^{4}$ Piedra angular en el programa poético ovidiano, según Galinsky 1999, p. 308.

${ }^{5}$ Cf. Kroener, H. O. 1917; Iodice di Martino 1981.

${ }^{6}$ Cf. Luque Moreno 1995; Otón Sobrino 1999.

${ }^{7}$ Cf. Flores 1999.

${ }^{8}$ Cf. González Vázquez 1993; Cicarelli 1997, p. 65-66.

${ }^{9}$ Cf. Ciccarelli 2003.

${ }^{10}$ De antipatía habla Holleman 1970 y 1971; para Coleman 1971 el eco de Horacio es un desafío tendencioso; de intención irónica hablan Segal 1969 y Moulton 1973; algunos, incluso, interpretan en clave irónica el adjetivo numerosus referido a Horacio en Tr. IV 10. 49, cf. Migliorini 1980, p. 56, n.2. Degl'Innocenti Pierini 1995 cree que Ovidio sentía la misma admiración por Horacio que por Virgilio, a los que consideraba no ya poetas sino uates.

${ }^{11}$ Véase en Alvar Ezquerra 1998 una tipología de los procedimientos intertextuales en la poesía latina.

${ }_{12}$ Cf. von Albrecht 1981b.

${ }^{13}$ Cf. Rosati 1979 
Este tipo de cuestiones las he tratado ya en otro trabajo ${ }^{14}$, del cual es complemento -aunque fue previo en el estudio del pasaje- este, en el que se comparan ambos textos, atendiendo a similitudes léxicas, morfológicas, sintácticas o incluso métrico-estilísticas si las hubiere, habida cuenta, no obstante, de la diferencia de metros en que están compuestos.

No pretendo presentar aquí un nuevo comentario de la oda horaciana ${ }^{15}$, ni tampoco de los versos ovidianos, sino un repaso de las concomitancias entre ambos textos, poniendo de relieve a la vez los nuevos matices que introduce Ovidio respecto a su modelo.

\section{EL CONTENIDO}

El pasaje de Ovidio, algo más breve que el de Horacio, incluye, sin embargo, casi todos los puntos y temas que trataba este: la rúbrica de la obra que finaliza, la obra imperecedera, la inmortalidad del poeta... Estos motivos no son exclusivos de estos dos autores ${ }^{16}$, obviamente: la alusión a la obra que se acaba y a algunas anteriores la encontramos por ejemplo en Virgilio, Georg. IV 563-566; el motivo del poeta que pervivirá gracias a ella se encontraba ya en Ennio (apud Cic., Tusc. I 34.117) y se encuentra también en Propercio III 1 y 2 ; y el propio Ovidio lo presenta en otros lugares ${ }^{17}$ como $\mathrm{Am}$. I 15 o $\mathrm{Tr}$. III $3.77-80^{18}$, IV 10.121-132, que comparten motivos con la oda horaciana, pero que no la evocan tan claramente.

Orgulloso de haber inaugurado un género poético en Roma, Horacio se parangonaba con los líricos corales, que le sirven de modelo para esta imagen que da comienzo a la oda; pero si en ellos la inmortalidad se refería a con-

${ }^{14}$ Hoces Sánchez 2012.

15 Abundantes y excelentes, como Iturgáiz 1952; Fraenkel 1957, p. 302 ss.; Fontán 1966; Syndikus 1973, pp. 272-282; West 2002, pp. 260-268; Nisbet-Rudd 2004 ad loc.

${ }_{16}$ Cf. Syndikus 1973, p. 273.

${ }^{17}$ En efecto, sobre todo en los poemas del destierro, son numerosos los pasajes que hablan del poder de la poesía para inmortalizar: Tr. III 7.43-52; IV 9.15-26; 14.1-14; Pont. II 6.33-34; IV 8.45-64. Llama la atención, como apunta González Vázquez 1992, la audacia que caracteriza a algunos de esos textos, como por ejemplo Tr. III 7.47-48: Ingenio tamen ipse meo comitorque fruorque:/ Caesar in hoc potuit iuris habere nihil.

${ }^{18}$ En este texto incluso utiliza el término monumentum: Hoc satis in titulo est; etenim maiora libelli/ et diuturna magis sunt monumenta mihi, / quos ego confido, quamuis nocuere, daturos/ nomen et auctori tempora longa suo. 
ceptos ajenos a la poesía (por ejemplo en Simónides, Fr. 531.4 ss. Page, a los honores debidos a los muertos de las Termópilas), Horacio traslada la idea de inmortalidad del objeto cantado al canto mismo y le confiere con ello un aire muy romano ${ }^{19}$. En efecto, el tema de la inmortalidad que procura la poesía puede rastrearse incluso hasta época indoeuropea, como señala Achcar 1991, pero, como él mismo afirma al final de su trabajo, negando la propuesta de Snell de considerar romana la concepción de la obra poética como «monumentum aere perennius, es verdad que en el momento en que Horacio escribe, el monumentum es el del poeta, no el del héroe». Y sigue: «También debe ser verdad que ello tiene relación con el hecho de que Horacio (como ya Píndaro) escribe, no compone oralmente, como en los tiempos de una sociedad arcaicamente más homogénea». Y si esto es válido para Horacio, en la misma medida lo es para Ovidio.

Ambos poetas dedican sus primeros versos a la obra que cierran: para Horacio, más prolijo, su obra es un monumento imperecedero y de una magnitud como no se conoce otro; no puede ser destruido por los elementos ni por el paso del tiempo. Para Ovidio su obra tampoco será destruida por ninguno de esos agentes. Horacio había parangonado su obra con grandes construcciones; Ovidio, en cambio, es más escueto en la referencia a su obra.

Los dos textos siguen, a su vez, con versos dedicados al poeta: Horacio asegura que no morirá en todas sus facetas, ya que mucha parte de él evitará la muerte y vivirá siempre renovado, unida su eternidad a la de las instituciones de la ciudad ${ }^{20}$. Ovidio, por su parte, parece asumir en mayor medida su muerte corporal y es más explícito en cuanto al momento incierto de la misma; a pesar de ella, también afirma que una parte de él, la mejor, se hará inmortal (ya que su lugar será el cielo, por encima de los astros), que su nombre no se borrará y que lo leerán allá por donde se extiende el poder de Roma.

Ambas composiciones continúan con la vida ulterior de cada uno de los poetas: Horacio se ufana de que todos hablarán de él, el poderoso de orígenes humildes, y dirán que aclimató la canción eolia a los modos itálicos. Ovidio, de forma muy similar, habla de la vida posterior a su muerte y hace alusión también a la extensión que alcanzará su fama si puede uno fiarse de lo que

\footnotetext{
19 Cf. Romano 1991, p. 843.

${ }^{20} \mathrm{El}$ tema de la eternidad de Roma, tan difundido en la literatura clásica y de época de Augusto, se presentaba ligado a la perdurabilidad de sus instituciones; cf. Dopico Caínzos 1998.
} 
anuncian los vates; falta en él, no obstante, la alusión a la tierra de origen, tan presente en Horacio, y en otros poetas (Propercio, Horacio, el propio Ovidio o Marcial $^{21}$ ) en lugares similares, y la alusión a sus logros poéticos, que un lugar tan destacado habían ocupado en la oda horaciana. Aquí acaba el texto de Ovidio. El de Horacio, en cambio, se prolonga todavía algo más de dos versos en los que se dirige a la Musa, en segunda persona, y le exige que reconozca sus méritos, que justifican la actitud soberbia que mantiene.

\section{EL LÉXICO}

Son varias las palabras horacianas que Ovidio repite en sus versos: algunas de forma literal incluso morfológicamente y referidas a los mismos conceptos; otras, en cambio, las refiere Ovidio a conceptos diferentes, pero resuenan como un eco de las de Horacio.

La primera palabra que llama la atención y la que más evoca a Horacio es sin duda el perfecto exegi: el uso del perfecto es típico de los lugares conclu$\operatorname{sivos}^{22}$, y es Horacio el primero en usar este verbo en conexión con monumentum $^{23}$; con esta juntura ${ }^{24}$, Horacio ha dado nueva vida a la palabra al describir su poesía como un monumento sepulcral, lo cual es congruente con la comparación con las pirámides y con la referencia a la muerte ${ }^{25}$, y en este sentido, la pieza podría considerarse una especie de carmen epigraphicum del propio Horacio, su epitafio poético ${ }^{26}$; como indica Korzeniewski, Ovidio toma esta juntura, aunque con un complemento diferente: opus.

Monumentum es todo aquello que hace recordar, es algo conmemorativo, de ahí que signifique de modo especial 'monumento funerario', y también

${ }^{21}$ Prop. I 22.3 y IV 1.61; Hor., Carm. IV 9.2; Ou., Am. II 1.1 y III 3; Mart. I 61.12, por citar solo algunos.

${ }^{22}$ Cf. Petersmann 1983, p. 1652, n. 18: «Perfekt ist häufig in Schlußgedichten».

${ }^{23}$ Cf. Korzeniewski 1968, p. 32.

${ }^{24}$ Cf. DRAE. s.v., 2. f. ant. junta (todo que forman varias cosas unidas).

${ }_{25}$ Para estas cuestiones, cf. Nisbet-Rudd 2004, ad loc.

${ }^{26}$ Cf. Gómez Pallarés 1994, p. 70 ss.; el autor considera que en Roma el término monumentum hacía pensar en un texto epigráfico sepulcral; en la misma línea habría que interpretar otras expresiones: aere perennius, ya que era el bronce el material sobre el que se ejecutaban muchas inscripciones; situs, asimilable al frecuentísimo hic situs est de las inscripciones funerarias; la alusión a las pirámides; la magnitud del monumento, que cuanto mayor era mejor y más tiempo conservaba la memoria del difunto; la indicación del origen (humili) y de los logros en vida (meritis)... En esta misma línea, cf. Korzeniewski 1968. 
'monumento escrito'; opus, por su parte, de sentido más general, 'obra, trabajo', indica muy frecuentemente 'edificio, estructura, construcción', de modo que Ovidio usa un término que no connota relación alguna con la muerte; Ovidio se ha liberado de la referencia a la arquitectura sólida y perenne de la sepultura (pues tampoco la compara con las pirámides, como sí había hecho Horacio), y parece que la obra desaparece ante su autor ${ }^{27}$.

El uso de un término más genérico quizá podía haber hecho perder fuerza a la expresión, pero esto no llega a ocurrir: el término opus se refiere siempre en Ovidio a obras públicas ${ }^{28}$, nunca privadas, y, en la aguda interpretación de Wickkiser, enlazaría con la reciente mención de Marte y Júpiter Tarpeyano, que representan llamadas a significativos edificios de Augusto, y es evidente el lugar central que ocupaba el programa edilicio en el principado de Augusto; al presentarse, pues, Ovidio como autor de su opus, no solo coloca su obra en el contexto del programa edilicio de Augusto sino que sugiere que su opus es una obra de arquitectura pública, un monumento en el espíritu del período; y, lo que es más, al comparar su creación con las de Augusto, se jacta de que la suya será más duradera.

En este sentido, también puede verse un vínculo estrecho entre la composición horaciana y la actividad constructora de esos años, como agudamente apunta Simpson 2002, no solo por el uso que Horacio hace en sus odas de realidades arquitectónicas existentes o imaginadas ${ }^{29}$ sino, lo que es más pertinente en nuestro caso, por utilizar imágenes de la construcción como metáfora de su producción literaria ${ }^{30}$.

${ }^{27}$ Cf. Courrént 2008, p. 265; la autora afirma que Ovidio está al final de la tradición literaria y por eso ha podido jugar con todos sus temas y llevarla a sus límites y que con él la literatura monumental se convierte en un monumento a la sola gloria de su autor, desvinculado de toda obligación hacia la figura imperial que había permitido su creación. Esa independencia es también la que le permite, utilizando las mismas imágenes que las que se leen en la $\mathrm{Me}$ tamorfosis, en Horacio o Virgilio, escribir sus últimos poemas. Así la última palabra la tiene el poeta; a pesar del exilio definitivo impuesto por Augusto, no sólo su nombre sino también su obra obtienen un renombre eterno.

${ }^{28}$ Tomo el dato y la interpretación de Wickkiser 1999, p. 122 ss. Su argumentación va encaminada a demostrar que la sphragís no debe considerarse al margen de la obra sino como continuación lógica de la misma y para ello advierte una serie de correspondencias (de contenido, léxicas...) de la sphragís tanto con el proemio como con los versos que la preceden. De todas formas, también en Rem. 811 se lee Hoc opus exegi, referido a la obra que llega a su término.

${ }^{29}$ Como ejemplo de ello valga la alusión al Capitolio en esta misma oda.

${ }^{30}$ Cosa que, por lo demás, Horacio comparte con otros poetas contemporáneos como Virgilio e incluso algún historiador, como Dionisio de Halicarnaso; cf. Simpson 2002, p. 61 ss. 
Un comentario queda todavía acerca del verbo exigo. Ya he dicho que es Horacio el primero en usarlo con monumentum como objeto, en lugar de los más habituales aedificare, locare, facere o absoluere; pues bien, tanto exegi como deducere son programáticos y apuntan a la estética alejandrina: exigo introduce un motto $^{31}$ pindárico, en la línea de subrayar la función y el valor de la poesía, «mientras que deducere define el proceso de introducción de la lírica eólica en la poesía latina» ${ }^{32}$.

Ovidio utiliza precisamente estos dos verbos en lugares poetológicos de las Metamorfosis como son el epílogo o sphragís para el caso de exigere, como acabo de comentar, y en el proemio para deduco, donde el verso 4, ad mea perpetuum deducite tempora carmen, apunta al ideal calimaqueo y a la estética alejandrina ${ }^{33}$, al referirse al entrelazado de poemas o sucesos, frente al carmen perpetuum que es la épica, intentando aunar términos en principio antitéticos. En esto tenía el ejemplo del virgiliano deductum ${ }^{34} \ldots$ carmen $(E c l$. VI 5), recusatio de la gran poesía épica, ejemplificado con una sucesión de episodios cantados por Sileno en orden cronológico desde los orígenes del mundo hasta Filomela y Tereo, canto que podría considerarse modelo para las Metamorfosis ${ }^{35}$.

La siguiente palabra que se repite idéntica es edax, aunque se refiere a sustantivos distintos en uno y otro texto. Horacio la refería a imber, uno de los elementos de la naturaleza que pese a su voracidad iba a ser incapaz de destruir su monumentum. Términos relacionados con 'morder' habían sido ya aplicados a la erosión causada por los ríos; no es extraño, pues, este uso por parte de Horacio, quien, no obstante, elige un término de gran fuerza como es edax; pero Ovidio aplica este término tan físico a un concepto abstracto como es uetustas ${ }^{36}$, y en ello, hasta donde sé, es Ovidio el primero: el adjetivo suele referirse en los textos a personas o animales, al fuego, a la lluvia, etc. Antes de Ovidio solo Horacio, Carm. II 11, 18, lo refiere a un sustantivo abstracto, cura; Ovidio también realiza ese tipo de juntura,

31 En palabras de Fraenkel 1957, p. 159.

${ }^{32}$ Cf. Nasta 2004, p. 176.

${ }^{33}$ Cf. Galinsky 1999 y Álvarez - Iglesias $2004^{6}$, p. 55 ss.

${ }^{34}$ El uso de este verbo aplicado a la poesía procede de su empleo para expresar la tarea de la hilatura, cf. TLL V, I, col. 279, 1. 76 ss.

${ }^{35}$ Cf. Otis 1966, p. 48 y Due 1974, p. 94 ss.

36 También en Met. XV 234 ss.: tempus edax rerum, tuque inuidiosa uetustas,/ omnia destruitis, uitiaque dentibus aeui/ paulatim lenta consumitis omnia morte. 
refiriendo el término a Liuor $^{37}$, pero es absolutamente el primero en asociarlo a conceptos temporales, como tempus ${ }^{38}$ o uetustas ${ }^{39}$, usos que retomarán algunos poetas con estos mismos sustantivos y algún otro como aetas $^{40}$ o Luctus $^{41}$.

El verbo possum también es repetido por Ovidio como predicado de la oración de relativo que, igual que en Horacio, depende del complemento de exegi. En este punto Ovidio se separa de Horacio, quien había utilizado el subjuntivo possit; Ovidio, en cambio, el indicativo poterit. A esto me referiré en el siguiente apartado, al tratar de la sintaxis de ambos pasajes.

Multa pars mei, en opinión de Nisbet-Rudd, da al tópico de la supervivencia tras la muerte un sentido diferente: el de que el poeta vivirá en sus poemas, que son una parte de él; Horacio usa aquí multa ${ }^{42}$ en lugar del más usual magna y de nuevo Ovidio, aunque sigue muy de cerca a Horacio en la idea de que es una parte de él la que sobrevivirá, difiere ligeramente de él y se atreve a calificar esa parte, atendiendo no ya a su magnitud sino a su calidad, como melior, lo que introduce no ya una constatación sino una valoración de la misma.

Por último, el adverbio relativo qua es usado por ambos autores para introducir las oraciones que establecen la extensión geográfica que alcanzará su fama.

Hasta aquí he pasado revista a las palabras horacianas que se repiten literalmente en Ovidio, seis si no se tienen en cuenta conjunciones y preposiciones, de una gran fuerza evocadora, sobre todo exegi en el verso inicial.

Ahora bien, Ovidio retoma varios conceptos de Horacio y los expresa mediante términos de los mismos campos semánticos: en Horacio los fenómenos naturales de la lluvia, imber, y el viento, Aquilo; en Ovidio los fenómenos y elementos naturales del rayo, Iouis ira, el fuego, ignis, y el hierro, ferrum; el paso del tiempo, annorum series et fuga temporum en Horacio, uetustas en Ovidio; como vemos se trata de conceptos muy cercanos en ambos poetas.

37 Am. I 15.1; Rem. 389. Después se encuentra esta misma juntura en Sen., Phaedr. 493, Lucan. I 288 y Mart. XI 33.3.

${ }_{38}$ Pont. IV 10, 7; Met. XV 234; después se encuentra en Ps. Sen., Epigr. 232, 1.

39 Tras este uso de Ovidio se documenta en Sen., Oed. 536.

${ }^{40}$ Lucan. VII 397.

${ }^{41}$ Sil. Ital., Pun. XIII 581.

${ }^{42}$ También en Ou., Am. I 15. 42: parsque mei multa supertes erit. 
En el caso de la Iouis ira, esta cercanía es posible si entendemos la expresión como referida al rayo, pero hay estudiosos que entienden que Ovidio se está refiriendo a la ira de Augusto ${ }^{43}$, que de este modo se haría presente en estos versos, como estaría presente en los de Horacio si se admite que el término princeps hace sentir la presencia de Augusto a cuya figura se equipara Horacio ${ }^{44}$, igual que Ovidio acaba de hacer presentando, mediante el uso del término opus, su obra como una obra pública al nivel de las de Augusto.

Si se piensa que ira Iouis puede ser Caesaris ira (como ya había dicho Ovidio en Tr. III 11.71: non est quod timeas: fortuna miserrima nostra est,/ omne trahit secum Caesaris ira malum) habría que admitir que la sphragis fue compuesta en el exilio, o al menos cuando ya Ovidio conocía el decreto de Augusto que lo confinaba en Tomi, lo que daría a esta afirmación una connotación marcada por una fina ironía ${ }^{45}$ que muy frecuentemente se ha supuesto en la actitud de Ovidio, o una especie de postura desafiante de poeta orgulloso sobre todo de sus obras amatorias, que aquí estaría haciendo extensiva a su obra más vasta.

Los verbos que, en primera persona, se refieren a la vida futura del poeta también se acercan en ambas composiciones: el trío moriar, crescam, dicar horaciano se ve reflejado en el ovidiano ferar, legar, uiuam, que no repite literalmente ninguno pero que repite los conceptos e incluso morfológicamente es semejante, pues ambos tríos están formados por dos futuros pasivos (en Horacio uno de ellos, moriar, es deponente) y uno activo. Por otra parte, es fácil ver el reflejo de los horacianos non omnis moriar, dicar y crescam recens en los ovidianos super alta perennis astra ferar, legar y uiuam, respectivamente, y de modo especial en los dos últimos.

En estas correlaciones se puede ver también un cierto lazo entre ferar ovidiano y dicar horaciano, pues, como apunta Wickkiser ${ }^{46}$, feror significa literalmente 'ser llevado', pero también 'ser relatado'. Es un inteligente juego de palabras sobre el mismo concepto el hecho de que los medios de inmor-

43 En general es así admitido, por ejemplo González Vázquez 1992, p. 268, adhiriéndose a la opinión de Herescu 1958, p. 432 s., quien, por lo demás, considera estos versos compuestos en el exilio y como pasaje paralelo al de Tr. IV 10.121-130; aunque hay quien no lo entiende de esa manera, por ejemplo Currie 1981, p. 2729, o Álvarez-Iglesias $2004^{6}$, pp. 106-107, para quienes la expresión sí tiene ese sentido en las obras del destierro, pero no aquí.

${ }^{44}$ Cf. Wickkiser 1999, p. 123, quien sigue en esto los planteamientos de Galinsky 1998.

${ }^{45}$ Cf. Segal 1969, p. 290 ss.

461999 , p. 135. 
talidad, el modo de transporte a un lugar más allá de las estrellas, sea la palabra. Ya «dicha»-dicar horaciano-, ya «leída»-legar ovidiano-, o como explícitamente dice Ovidio, mediante la fama, en su sentido etimológico -de la misma raíz que el verbo for, pr. ${ }^{*} b^{h} e^{h}{ }_{2}-{ }^{*} b^{h} h_{2}$, ' 'hablar'- es la palabra la que hace que el poeta viva, y lo hará porque hablarán de él (dicar horaciano y un posible sentido de ferar ovidiano, que aunque en este texto tenga principalmente el de 'seré llevado' no deja de hacer resonar en los oídos el de 'se hablará de mí') y porque lo leerán (legar). Como complemento de legar el ablativo ore evoca también la famosa frase de Ennio, apud Cic., Tusc. I 34.117: Nemo me lacrimis decoret nec funera fletu faxit. Cur? uolito uiuos per ora uirum.

La imagen de super astra, por lo demás, no tiene precedente en las afirmaciones del poder de la poesía.

Así, la priamel que precede a la sphragis en realidad no culmina con Augusto: su clímax es Ovidio en persona en la sphragís, donde compara su creación con las muchas del princeps y se jacta de que la suya será más duradera. Si Augusto ascendió ad astra, Ovidio avanzará aún más, super astra; es significativo, por otra parte, el hecho de que los versos dedicados a Augusto acaben con el término absens mientras que los dedicados a la obra y su autor, que además cierran el poema, lo hagan con el rotundo uiuam.

Por último, resuenan en los versos de Ovidio términos que aparecían en Horacio, aunque aplicados a conceptos diferentes, como el perennius referido al monumentum horaciano y el perennis de Ovidio referido a sí mismo; o el término potens de Horacio, referido a sí mismo, que resuena en la Romana potentia de Ovidio. Estos términos, insisto, no son usados por Ovidio para referirse a las mismas cuestiones a las que Horacio los refirió, pero no dejan de hacer sonar al autor lírico en el épico.

\section{LA SINTAXIS}

Veamos la estructura sintáctica de los dos pasajes: Horacio comienza su oda con una breve afirmación en oración independiente, exegi monumentum, que se expande, pues de monumentum dependen dos adjetivos comparativos, perennius y altius y sus respectivos términos de comparación; sigue una oración de relativo con un sujeto cuádruple (imber edax, Aquilo impotens, annorum series y fuga temporum). Tras esta oración independiente, siguen otras tres oraciones independientes en futuro, dos de las cuales tienen el verbo en voz 
pasiva: moriar (deponente), crescam y dicar; la de moriar está coordinada a la de uitabit, la de crescam lleva una subordinada temporal, dum ... scandet, y la de dicar lleva dependiendo de ella una oración de infinitivo, deduxisse, y dos circunstanciales en anáfora, qua ... obstrepit y qua ... regnauit. Por último, dos imperativos, sume y cinge, introducen el apóstrofe final a Melpómene.

Ovidio comienza igualmente con una afirmación en oración independiente y de la misma concisión que la de Horacio, iamque opus exegi, y de opus depende a su vez una oración de relativo de sujeto también cuádruple (Iouis ira, ignis, ferrum y uetustas); sigue la oración de cum uolet, subordinada temporal de una oración independiente con verbo en subjuntivo, finiat, de cuyo sujeto illa dies depende una oración de relativo, quae ... habet. A continuación, tres oraciones independientes coordinadas entre sí, con verbos en primera persona de futuro, como las horacianas moriar, crescam y ferar, y también dos de ellos en voz pasiva, ferar, legar y uiuam, cierran el pasaje y el último, la obra. De legar depende una oración subordinada circunstancial del mismo tipo y con la misma conjunción que en Horacio, qua ... patet; la oración independiente de uiuam, va precedida, finalmente, de una subordinada condicional, siquid... habent, que introduce una restricción a la veracidad de las palabras que acaba de expresar.

Como se ve, la sintaxis presenta muchos puntos de contacto.

La oración de relativo, quod, con sujeto múltiple, presente en los dos textos tiene como predicado el mismo verbo en ambos: possum. Pero ya he aludido al hecho de que en Horacio la oración de relativo lleva el verbo en subjuntivo, possit, mientras que en Ovidio el verbo está en indicativo, poterit.

Varias apreciaciones cabe hacer a este respecto. La primera, y quizá más obvia, es la cercanía entre el futuro latino y el subjuntivo ${ }^{47}$, morfológica diacrónicamente y funcional sincrónicamente, en tanto que el futuro asume, junto a su valor habitual de indicativo, o real, y temporal, valores que lo convierten en «vehículo para la expresión de hechos no reales».

Por otra parte, las distintas explicaciones que ha recibido el subjuntivo en las oraciones relativas suelen estar de acuerdo en apuntar matices finales, consecutivos, causales, etc. para las mismas, sin olvidar que esos matices dependen de la relación semántica entre los predicados de la oración principal y la oración de relativo ${ }^{48}$. Una explicación muy sencilla, pero que en este caso viene a

${ }^{47}$ Cf. Baños Baños 2009, p. 463 ss.

${ }^{48}$ Ibíd. p. 586 ss. 
apoyar una impresión que la lectura del pasaje ovidiano -en conexión con otros del mismo autor- me produce, se encuentra en Rubio 1981, pp. 289-291 y Rubio Fernández-González Rolán 1985, §§ 378-387: las oraciones de relativo con el verbo en indicativo no se subordinan a la oración de la que dependen en su conjunto sino a un elemento de la misma, al que determinan, circunscriben o definen; en cambio, las relativas cuyo verbo está en subjuntivo establecen una relación recíproca con el verbo de la oración de la que dependen, además de la relación con el elemento que es su antecedente. El valor circunstancial que suelen tener estas últimas daría a la oración de Horacio un valor final o consecutivo que, digamos, es intencional; es decir, Horacio exegit monumentum con la intención y finalidad de que no pueda ser destruido; en cambio, el indicativo de Ovidio prescindiría de ese valor, de modo que la oración relativa es más referencial, no se proyecta hacia una finalidad, y no parecería que Ovidio haya completado su obra con una intención sino que esta, su obra, espontáneamente ha surgido con una cualidad, expresada por la oración de relativo, y que es la de ser indestructible. Esta espontaneidad de la poesía ovidiana casa bien con un rasgo que la caracteriza desde su proceso mismo de generación y desde los primeros y jóvenes pasos del poeta en esta actividad, como el propio Ovidio confesaba en su autobiografía de $T r$. IV 10.24-26:

motus eram dictis, totoque Helicone relicto

scribere temptabam verba soluta modis.

sponte sua carmen numeros veniebat ad aptos,

et quod temptabam scribere versus erat.

Ambos autores, al pasar al poeta mismo como centro de interés, se expresan de modos semejantes: una secuencia de tres oraciones independientes, en futuro, dos de ellas en futuro pasivo; en ambos se encuentran también subordinadas circunstanciales introducidas por el mismo nexo, qua, en Horacio subordinada a la oración de dicar y en Ovidio a la de legar y en ambas, por último, hay una subordinada temporal, aunque de distinto tipo: en Horacio, la oración introducida por dum liga la perdurabilidad de su fama a la permanencia de las instituciones romanas, como se ha dicho; en Ovidio, la oración temporal introducida por cum marca el momento en que la muerte física ${ }^{49}$ del poeta dará paso a su inmortalidad, a su apoteosis ya que será llevado super astra.

${ }^{49}$ Como afirma Korzeniewski 1972, p. 388, es frecuente en el poema que cierra un libro el antagonismo entre la muerte y la inmortalidad. 
El reparto de las personas verbales es semejante en ambos autores: casi la mitad de ellas se refieren a la primera persona. De los once verbos en forma personal que aparecen en Horacio, cuatro están en primera persona, dos en segunda y cuatro en tercera; el verbo restante es una tercera persona, uitabit, pero con un sujeto multa pars mei que lo acerca a la primera. En Ovidio, de los diez verbos en forma personal, cuatro están en primera persona y cinco en tercera; el verbo restante está en tercera persona, erit, pero, también aquí, con un sujeto nomen nostrum que lo acerca a la primera.

Como se ve, faltan en Ovidio los verbos en segunda persona ${ }^{50}$, lo cual en principio es lógico dado el género de la obra, a diferencia de la lírica en la que es habitual el apóstrofe al lector o, como en este caso, a la divinidad. Pareciera que Ovidio se haya frenado en esto: ha ido quizá demasiado lejos apareciendo de nuevo (ya lo había hecho al principio) al final de su obra y utilizando como modelo un texto lírico en una obra que no $10 \mathrm{es}^{51}$; echar mano de un apóstrofe al lector o a la divinidad, hacer que el lector no solo oiga la voz del poeta épico hablar de sí mismo, sino que además lo oiga llamándole la atención a él, lector, o a un personaje externo a la obra, tal vez habría sido sobrepasar los límites permitidos a una composición larga en hexámetros, que, al margen de las consideraciones acerca del género al que pertenecen las Metamorfosis, tenía todo el aire de una obra épica.

Lo cierto, por otra parte, es que Ovidio se muestra en muchas ocasiones osado (ver n. 18), y en estos mismos versos lo ha sido cuando ha desafiado la ira de Augusto (si interpretamos así la expresión Iouis ira), y cuando ha aludido sutilmente a él afirmando que ha hecho un opus imperecedero, rasgo que no parecían tener otros opera del momento, entiéndase las obras públicas promovidas por Augusto.

Resumiendo, pues, la estructura sintáctica ovidiana se acerca a la horaciana en varios elementos: el exegi inicial del que depende un objeto al que van referidas sendas oraciones de relativo, con sujeto cuádruple en los dos textos, cuyo verbo es, también en ambos, possum; los tríos de verbos en primera persona del futuro en oraciones independientes, coordinadas entre sí en Ovi-

${ }^{50}$ Solo aparecen dos en toda la obra, pero han de interpretarse como impersonales y no dirigidos al lector; cf. von Albrecht 1981a, p. 225.

${ }_{51}$ Sobre el género y los rasgos a veces incluso líricos de las Metamorfosis cf. Merli 2004, Álvarez-Iglesias 20046, p. 97; en opinión de Estefanía 1999, Ovidio traspasa de un modo claro los límites genéricos; en su producción no hay distinción tan clara entre géneros como en Virgilio. 
dio, y la oración subordinada (doble en Horacio) introducida por el adverbio relativo qua.

\section{Métrica y estilística}

La métrica, en principio, es un punto de desunión más que de similitud entre los dos textos; con todo, hay quien apunta incluso paralelos rítmicos, pese a la diferencia de metro ${ }^{52}$.

La composición de Horacio, en asclepiadeo menor, lo sitúa en la línea de la lírica eólica, por lo demás citada explícitamente en el poema. Ovidio compone hexámetros, lo cual sitúa su obra en un ámbito literario bien diferente: el de la épica, la bucólica, la didáctica.

Versos de tradición isosilábica, unos, frente al verso por pies por antonomasia, el otro, con tan pocos puntos de unión lo único que podría estudiarse al unísono en ambas versificaciones serían como mucho cuestiones de tipología verbal ${ }^{53}$, teniendo en cuenta los tipos rítmicos y los tipos métricos ${ }^{54}$ que se dan en una y otra composición, o más bien cuestiones de estilística en conexión con la métrica.

La simple elección de una forma métrica u otra ya es en sí un estilema, pues supone una caracterización literaria precisa; la elección de distintos esquemas de una misma forma (aquellas que lo permiten) también caracterizan un texto; pero es sobre todo en el nivel de la composición donde es más visible la relación entre métrica y estilística, pues las posibilidades de variación y de elección son infinitamente mayores al entrar en contacto la estructura métrica con el material lingüístico, empleado a su vez en clave estilísti$\mathrm{ca}^{55}$ : cuestiones como el uso de determinadas palabras y lugares que ocupan en el verso, la relación entre el verso y la frase, etc.

Desde el punto de vista más estrictamente métrico, la composición de los asclepiadeos responde a la norma para estos versos; no podía ser de otro modo pues es Horacio el que la fija con su praxis versificatoria: la base es

52 Cf. Buisel 2003, pp. 276-277, que ve un eco rítmico del horaciano multaque pars mei en el ovidiano parte tamen meliore mei.

${ }^{53}$ Véase el breve y agudo comentario al respecto de Fontán 1966.

${ }^{54}$ Es decir, los tipos de palabras en cuanto a su estructura prosódica en la cadena hablada (tipo rítmico), y las diversas posibilidades que un tipo de palabra tiene de aparecer en un verso concreto (tipo métrico); cf. Luque Moreno 2000.

${ }^{55}$ Un esbozo de todas estas relaciones se puede leer en Luque Moreno 1998. 
siempre espondaica y hay cesura en la sexta sílaba, tras el primer grupo coriámbico, en todos los versos (en algunos de ellos, vv. 1, 7 y 12, en elisión); en la composición de Ovidio los versos se atienen a la norma del hexámetro augustal en cuestión de cesuras y de esquemas preferidos: por ejemplo el primer pie preferentemente dactílico (en los nueve versos es así), lo que a su vez lo mantiene alejado del comienzo espondaico de los asclepiadeos; las cesuras que se observan son las más frecuentes en este tipo de verso, penthemímeres en todos los versos salvo el verso 875, que presenta la triple A. Por tanto, ambas composiciones coinciden en atenerse a la forma y estructura clásicas para sus respectivos tipos de versos, algo de esperar teniendo en cuenta los autores de que se trata.

El hexámetro, en teoría, admite las palabras de cuatro semipiés, pero de hecho son difíciles de encajar y, de acuerdo con esta norma, son pocas las palabras cuatrisílabas en estos versos; por ejemplo, Ovidio no utilizó el comienzo de Horacio, exegi monumentum (cuya estructura prosódica, si era seguida de sílaba de cantidad larga, le permitía aparecer en un verso dactílico); esto habría dado lugar a un hexámetro sin cesura penthemímeres, ni posibilidad de triple A, lo cual, si no imposible, sí habría sido bastante extraño. Así pues, en la composición ovidiana los cuatrisílabos son mucho menos frecuentes que en la horaciana: 11 en Horacio (monumentum, perennius, pyramidum, diruere, Libitinam, agrestium, populorum, Aeolium, deduxisse, superbiam, Melpomene) frente a 4 en Ovidio (abolere, meliore, potentia, praesagia). Palabras más largas, de cinco sílabas o más, se encuentran también en uno y otro texto, pero muy escasamente: en Horacio Capitolium e innumerabilis, indelebile en Ovidio.

Ahora bien, desde el punto de vista estilístico se observa una cierta similitud en la organización de ambos textos.

El carmen de Horacio, con la apódosis final breve, como es habitual, tras una expositio más larga, en el que se adivinan las partes de un discurso de género demostratiuum, se articula siguiendo la ley de los miembros crecientes ${ }^{56}$ : el monumentum ocupa dos versos, vv. 1-2; la oración de relativo dependiente de él ocupa los tres siguientes, vv. 3-5; el poeta ocupa los nueve siguientes, vv. 6-14, donde se podría establecer una subdivisión: la inmortalidad del poeta ocupa cuatro versos, vv. 6-9, y su fama, algo más de cuatro, vv. 10-14; en este comienza el apóstrofe final, que ocupa dos versos y medio, vv. 14-16.

\footnotetext{
${ }^{56}$ Cf. Fontán 1966.
} 
El mismo principio organizativo ${ }^{57}$ parece sustentar el texto de Ovidio, en el que el opus ocupa solo la mitad del primer verso, v. 871; la oración de relativo llega hasta el final del siguiente verso, y ocupa verso y medio, vv. 871-872; la alusión a su muerte material (algo ausente en Horacio) ocupa los dos versos siguientes, vv. 873-874; y la inmortalidad y la fama del poeta ocupan, en fin, los últimos cinco versos, vv. 875-879.

Esta estructura discursiva, en el sentido de que el texto es en sí un discurso completo, natural en el caso de Horacio, pues cada poema, cada oda, es un texto, un discurso en sí, quizá pueda sorprender algo más en Ovidio, en cuya obra estos nueve versos se añaden a los miles de versos que los preceden: por un lado, aun considerando, como hacen algunos, el epílogo o sphragís no como un añadido sino como parte integrante de la obra $a b$ initio, es evidente que los versos constituyen un todo en sí mismos, en cierto modo separados de la obra en la que se incluyen; por otro lado, es lógico, atendiendo a esta estructura completa, cerrada y perfecta, pensar que los versos fueron concebidos y surgieron después de haber sido finalizada la obra, y por tanto fueron compuestos como un pequeño poema que se añadió al gran poema que los precede.

\section{Conclusión}

A modo de conclusión diré que con el recurso a paralelos léxicos, morfológicos, sintácticos y estilísticos Ovidio ofrece una retractatio no solo conceptual sino, lo que es más llamativo, formal. No son muchas las palabras de Horacio que encontramos tal cual en Ovidio, pero son de una resonancia tal que no dejan espacio para la duda sobre qué autor las utilizó antes. En esto, sin duda, el exegi inicial lleva la mayor carga de evocación: es la campanilla que llama la atención, que nos trae a la memoria a Horacio y que nos hace esperar lo mismo que el lírico dijo acerca de él y su obra; esas expectativas se cumplen de forma delicada pero evidente, personal pero evocadora, con la repetición de unas pocas palabras exactas, algunas otras muy cercanas, con la alusión sutil a Augusto en ambas composiciones (Horacio mediante el término princeps; Ovidio mediante opus y quizá Iouis ira) y con la estructura en miembros crecientes que van desde la oración de relativo con sujeto múltiple al

${ }^{57}$ Con las salvedades de la alusión a la muerte física en Ovidio, ausente en Horacio, y el apóstrofe final a la Musa en Horacio, ausente en Ovidio. 
yo inmortal del poeta, sustentado todo ello en una sintaxis cercana en ambos textos a lo largo de varios versos.

Mediante esta alusión a Horacio, Ovidio nos hace ver que sentía por su obra tanto orgullo como Horacio por sus Carmina. No sabemos si los versos fueron compuestos ya en el exilio; quizá haya que inclinarse por esta idea, pues es en las obras del destierro en las que más reflexiones sobre su propia poesía se encuentran ${ }^{58}$, y si en esas circunstancias, echando la vista atrás sobre sus Metamorfosis, tuvo la idea de acabarlas con un broche digno, también en esas circunstancias nos relata, Tr. I 7 17-26, que tuvo la intención de destruirlas quemándolas, pero no pudo lograrlo pues existían ya numerosas copias: la equiparación con la Eneida de Virgilio es evidente. De este modo, Ovidio sitúa su obra a la altura de las de estos dos uates, de los que habla también desde su destierro ${ }^{59}$ ( $T r$. IV 10.42: temporis illius colui fouique poetas, / quotque aderant uates, rebar adesse deos).

Séneca (Suas. 3.7) dijo que Ovidio imita a Virgilio non subripiendi causa sed palam mutuandi, hoc animo ut uellet agnosci ${ }^{60} \mathrm{y}$ creo que, en esta composición, se puede afirmar lo mismo respecto a Horacio.

\section{BiBLIOGRAFÍA}

Achcar, F. 1991: «As fontes do topos horaciano Exegi monumentum», en Mito, religião e sociedade: (atas do II congresso nacional de estudios clássicos), São Paulo, pp. 191-195.

Albrecht, M. von 1981a: «Dichter und leser- am Beispiel Ovids», Gymnasium 88, pp. 222-235.

Albrecht, M. von 1981b: «Ovide et ses lecteurs», Revue des études latines 59, pp. 207-215.

Alvar Ezquerra, A. 1998: «Tipología de los procedimientos intertextuales en la poesía latina antigua», IX congreso español de estudio clásicos. 5, Madrid, pp. 3-16. Álvarez, C. e Iglesias, R. Ma . (ed. y trad.) 20046: Ovidio, Metamorfosis, Madrid.

${ }^{58}$ Cf. Hoces Sánchez 1995.

${ }^{59}$ En opinión de Degl'Innocenti Pierini 1995 Ovidio en estos versos se refiere especialmente a Virgilio y Horacio con el término uates, como figuras al margen y por encima de los poetas de su tiempo, a los que sí trató.

${ }^{60}$ Entre los antiguos era clara la distinción entre imitatio, el estudio y despliegue visible de rasgos reconociblemente característicos del estilo, una aceptable e incluso normal reutilización, y furtum, práctica que era condenada. Cf. Oxford Classical Dictionnary, svv. imitatio y plagiarism. 
Baños Baños, J. M. (coord.) 2009: Sintaxis del latín clásico, Madrid.

Buisel, M. D. 2003: «Un motivo recurrente: la inmortalidad del poeta (de Píndaro, Pítica VI 5-14 a Marcial, VIII 3 y X 2)», en Koronís. Homenaje a Carlos Ronchi March, Buenos Aires, pp. 267-283.

Ciccarelli, I. 1997: «Ovidio, Tristia 4, 10 e i topoi della sphragís», Aufidus N.S. 32, pp. 61-92.

Ciccarelli, I. 2003: «Da Orazio a Ovidio: 'lezioni di letteratura' a confronto», Euphrosyne 3, pp. 317-326.

Coleman, R. 1971: «Structure and intention in the Metamorphoses», CQ 21, pp. 459-477.

Courrént, M. 2008: «Nomen erit indelebile nostrum: Auguste et la littérature monumentale», Euphrosyne 36, pp. 257-268.

Currie, H. M. 1981: «Ovid and the roman stage», ANRW 2, № 31. 4, pp. 2701-2742.

Degl'Innocenti Pierini, R. 1995: «Numerosus Horatius. Aspetti della presenza oraziana in Ovidio», en Setaioli, A. (ed.), Orazio: umanità, politica, cultura. Atti del convegno di Gubbio 20-22 ott. 1992, Perugia, pp. 101-116.

Dopico Caínzos, M. D. 1998: «Le concept de l'aeternitas de Rome. Sa diffusion dans la société romaine», LEC 66, pp. 259-279.

Due, O. S. 1974: Changing forms. Studies in the Metamorphoses of Ovid, Copenhague.

Estefanía, D. 1999: «Ovidio, Quintilano y el “canon” literario», en Ovid, Werk und Wirkung, Festgabe für Michael von Albrecht zum 65. Geburtstag, 2 vol., her. W. Schubert, Studien zur klassichen Philologie 100, Frankfurt am Main, vol. II, pp. 829-840.

Flores, E. 1999: «Lucrezio in Ovidio», en Ovid, Werk und Wirkung, Festgabe für Michael von Albrecht zum 65. Geburtstag, 2 vol., her. W. Schubert, Studien zur klassichen Philologie 100, Frankfurt am Main, vol. I, pp. 35-40.

Fontán, A. 1966: «Análisis estructural de la poesía: un comentario a Horacio, Od. III 30», EClás 10, pp. 123-133.

Fraenkel, E. 1957: Horace, Oxford.

Galinsky, K. 1998: Augustan culture: an interpretative introduction, Princeton.

Galinsky, K. 1999: «Ovid's poetology in the Metamorphoses», en Ovid, Werk und Wirkung, Festgabe für Michael von Albrecht zum 65. Geburtstag, 2 vol., her. W. Schubert, Studien zur klassichen Philologie 100, Frankfurt am Main, vol. I, pp. 305-314.

Gómez Pallarés, J. 1994: «Horacio y la musa epigraphica», Euphrosyne 22, pp. 63-80.

González Vázquez, J. 1992: «Poesía e inmortalidad en las elegías ovidianas del destierro», FlorIlib 3, pp. 261-269. 
González Vázquez, J. 1993: «En torno a la retractatio de un pasaje virgiliano en Tristia I, 1», Latomus 52, pp. 75-83.

Herescu, N. I. 1958: «Le sens de l'epitaphe ovidienne», en N. I. Herescu (ed.) Ovidiana. Recherches sur Ovide, París, pp. 420-442.

Hoces Sánchez, M. C. 1995: «Métrica y música en Ovidio: las obras del destierro», FlorIlib 6, pp. 245-271.

Hoces Sánchez, M. C. 2012: «Los últimos versos de las Metamorfosis de Ovidio: una sphragís con ecos horacianos», en Luque, J. - Rincón, $\mathrm{M}^{\mathrm{a}}$. D. - Velázquez, I. (eds.), Dulces Camenae, Poética y poesía latinas, Granada, pp. 109-121.

Holleman, A.W.J. 1970: «Ovid, Tr., IV, 10, 50», Latomus 29, pp. 503-504.

Holleman, A.W.J. 1971: «Ovid and Politics», Historia 20, pp. 458-466.

Hornblower, S. y Spawforth, A. (eds.) 2003³: Oxford Classical Dictionary, Oxford. Iodice di Martino, M. G. 1981: «Ovidio e la poesia», RCCM 23, pp. 63-108.

Iturgáiz, X. 1952: «Exegi monumentum», Helmantica 2, pp. 427-440.

Korzeniewski, D. 1968: «Monumentum regali situ pyramidum altius, (Zu Hor. C. 3, 30)», Mnemosyne 21, pp. 29-34.

Korzeniewski, D. 1972: «Exegi monumentum. Hor. carm. 3, 30 und die Topik der Grabgedichte», Gymnasium 79, pp. 380-388.

Kroener, H. O. 1917: «Ovidio y los poetas», EClás 15, pp. 99-110.

Luque Moreno, J. 1995: «Tibulo a través de Ovidio», Emerita 63, pp. 341-351.

Luque Moreno, J. 1998: «Métrica y estilística: líneas generales», FlorIlib 10, pp. 201-210.

Luque Moreno, J. 2000: «Métrica verbal: ‘tipos rítmicos' y 'tipos métricos'», Florllib 11, pp. 121-135.

Merli, E. 2004: «On the number of books in Ovid's Metamorphoses», CQ 54, pp. 304-307.

Migliorini, P. 1980: «Osservazioni di critica letteraria in Ovidio: il giudizio su Lucrecio in Am. I 15, 24-25», Prometheus 6, pp. 56-66.

Moulton, C. 1973: «Ovid as anti-augustan: Met. 15, 843-79», CW 67, pp. 4-7.

Nasta, M. 2004: “"Aere perennius”: identidad poética y memoria colectiva en Horacio, Carm. 3, 30», Euphrosyne 32, pp. 173-184.

Nisbet, R.G.M. y Rudd, N. 2004: A commentary on Horace: "Odes», book III, Oxford.

Otis, B. 1966: Ovid as an epic poet, Cambridge.

Otón Sobrino, E. 1999: «Tibulo en Ovidio», en Ovid, Werk und Wirkung, Festgabe für Michael von Albrecht zum 65. Geburtstag, 2 vol., her. W. Schubert, Studien zur klassichen Philologie 100, Frankfurt am Main, vol. I, pp. 153-155.

Pohlenz, M. 1913: «Die Abfassungszeit von Ovids Metamorphosen», Hermes 48, pp. 1-13. 
Paratore, E. 1958: «L'evoluzione della "sphragís" dalle prime alle ultime opere di Ovidio», Atti del convegno internazionale ovidiano, Sulmona, pp. 73-203.

Petersmann, G. 1983: «Cornelius Gallus und der Papyrus von Qasr Ibrim», ANRW II No 30. 3, pp. 1649-1655.

Romano, E. 1991: Q. Orazio Flaco, Le opere, I: le odi, il carme secolare, gli epodi, tomo II, comm. di Elisa Romano, Roma.

Rosati, G. 1979: «L'esistenza letteraria. Ovidio e l'autocoscienza della poesia», $M D$ 2, pp. 101-136.

Rubio, L. 1981: Introducción a la sintaxis estructural del latín, Barcelona.

Rubio Fernández, L. y González Rolán, T. 1985: Nueva Gramática Latina, Madrid.

Segal, Ch. 1969: «Myth and philosopy in the Metamorphoses. Ovid's Augustanism and the Augustan conclusion to book XV», AJPh 90, pp. 257-292.

Simpson, C. J. 2002: «Exegi monumentum: building imagery and metaphor in Horace, Odes 1-3», Euphrosyne 30, pp. 57-66.

Syndikus, H. P., 1973: Die Lyrik des Horaz. Eine Interpretation der Oden, Band II, Drittes und viertes Buch, Darmstadt.

West, D., 2002: Horace Odes III. Dulce Periculum, Oxford.

Wickkiser, B. L. 1999: «Famous last words: putting Ovid's sphragis back into the Metamorphoses», MD 42, pp. 113-142.

Fecha de recepción de la primera versión del artículo: 21/11/2014

Fecha de aceptación: 23/03/2015

Fecha de recepción de la versión definitiva: 27/04/2015 